\title{
ALMEIDA GARRET, UM AUTOR ENGAJADO
}

Edson Santos Silva ${ }^{1}$

Wilma Rigolon ${ }^{2}$

RESUMO: O presente artigo tem como objetivo descortinar a produção literária de Almeida Garrett, em especial a dramática, com o fito de mostrar o amadurecimento de um claro projeto literário tendo como ponto norteador a idéia de um teatro didático e a releitura do presente português à luz alegórica do passado.

PALAVRAS-CHAVE Garrett; teatro; alegoria.

ABSTRACT: This article focuses on the literary production of Almeida Garrett, especially his dramatic work, with the purpose of showing the development of a clear literary project, based on the idea of a didactic theater and the rereading of the present in Portugal through the allegorical light of its past.

KEYWORDS: Garrett; theater; allegory.

\footnotetext{
${ }^{1}$ Doutorando em Literatura Portuguesa- USP

${ }^{2}$ Mestre em Língua Portuguesa- PUC/SP
} 
Aos vinte anos de idade, Almeida Garrett, introdutor do Romantismo em Portugal, confessou que iria assumir uma profissão de fé. Segundo esse autor, o poeta deveria ser também um cidadão politicamente consciente. Estabeleceram-se, a partir desse momento, as duas facetas inseparáveis presentes na obra garrettiana, sobretudo teatral: a do artista e a do homem político.

Dessa forma, sua obra pode ser considerada engajada, não meramente panfletária, mas no sentido clássico do docere cum delectare (educar com prazer). Essa adesão foi evidente a ponto de ser percebida de forma clara em vários de seus escritos, em especial naqueles em que se dedicou à reflexão literária, como os prefácios das obras teatrais, as três versões de Retrato de Vênus.

Para a realização deste trabalho serão discutidos os prefácios de suas obras dramatúrgicas sem, contudo, descurar de outros textos em que Garrett patenteou a intenção de pôr sua obra a serviço do momento político em que viveu.

No prefácio de Afonso de Albuquerque ${ }^{3}$ (1819) esboça-se esse projeto, cujo objetivo, num primeiro momento, seria o de despertar nos leitores anseios de virtude, consciência e cidadania por meio de heróis antigos. O prefácio acentua, de forma breve e clara, as escolhas feitas pelo autor: gênero literário, paradigmas, objetivo e o papel do artista diante de tal projeto, assim como a função precípua de uma obra de arte.

A poesia assim como todas as boas-artes só então adquirem um grau de esplendor, e sublimidade, que as fazem superiores a todos os outros humanos inventos, quando aprimoram em mandar à eternidade os beneméritos da pátria, e os feitos dos cidadãos dignos de imortalidade. (GARRETT, 1966, v. II, p.1993)

É, pois, com o entusiasmo de uma seiva nova que Garrett, empenhado na regeneração da Pátria, afirma, em 1819, que “o poeta é também cidadão”, cujo primeiro dever é

celebrar as virtudes dos seus compatriotas, e fomentá-las por este meio no coração dele. Se Homero contribuiu para formar a grande alma de Alexandre com o exemplo de Aquiles, quanto maior força devem ter sobre os ânimos bem nascidos os modelos de virtude, e esforços de concidadãos, a avoengos. (GARRETT, 1966, v. II, p. 1993-4)

O inacabado Afonso de Albuquerque foi, de todas as obras póstumas, a única que o autor tencionava publicar em vida. A tragédia, que deveria ter três atos, ficou apenas com dois incompletos. Garrett iniciou-os no Porto, em julho de 1819, e escreveu para eles um prólogo sem data. 
Ao citar Homero, evidencia-se a fonte de inspiração: os clássicos gregos, cuja literatura, em sua ótica, teria contribuído para a formação de bons cidadãos. Tal opção está em consonância com a sua formação neoclássica, reafirmada também no prefácio de Catão:

Lendo Sófocles e Ésquilo, Eurípides e Aristófanes- ajudando-me, no pouco conhecimento da língua grega, das boas traduções latinas e francesas, e sobretudo da erudita e engenhosa do P. Brumoy- adquiri o gosto do teatro clássico e das belezas grandes e símplices da Melpómenes de Atenas. (GARRETT, 1966, v. II, p. 1608)

Em 1820, no prefácio da obra Átala, Garrett afirmava:

Todos nós temos os nossos preconceitos, as nossas manias, e em conseqüência, vemos todas as cousas por elas, e as olhamos e estimamos pelo lado por que as lisonjeiam mais. Tudo referimos a um ponto, tudo quiséramos que viesse a ele, que é o foco, o centro da nossa paixão dominante. $\mathrm{O}$ meu foi sempre o teatro: qualquer ação por pouco trágica, qualquer fato, por pouco ridículo que fosse, me suscitaram sempre a idéia de uma tragédia, ou de uma comédia. (GARRETT, 1966, v. I, p 1969)

Em 1822, ano da publicação de Catão, fazia uma confissão sincera e apaixonada a respeito da Literatura Dramática, afirmando conhecer perfeitamente as dificuldades desse gênero. Assim, se o gênero dramático é, para Garrett, de grande dificuldade, por que sua preferência pelo teatro?

Aventa-se que o apego do autor pelo teatro deve-se a seu comprometimento político, além da crença de que a arte dramática deve ser "útil à coletividade". Segundo o dramaturgo, e graças à sua formação clássica, a arte deveria ser portadora de uma noção extremamente moralizadora, daí sua utilidade. Esta idéia será retomada anos mais tarde, quando, já um romântico moderado, afirma, em 1843, que cabe ao drama revestirse "das formas mais populares e derramar assim pelas nações um ensino fácil, uma instrução intelectual e moral que, sem aparato de sermão ou prelecção, surpreenda os ânimos e os corações da multidão, no meio de seus próprios passatempos." (GARRETT, 1966, v. II, p. 1086) 
Portanto, para Garrett, o teatro teria a função de espelhar os problemas da sociedade, tendo uma vantagem sobre as outras manifestações artísticas, a de atingir um público maior.

Levado por tais considerações, o autor dará à cena portuguesa a tragédia Catão, escrita em 1821, pondo em prática o projeto anteriormente defendido em Afonso de Albuquerque e, dentro de seu projeto de artista engajado, lerá sua contemporaneidade de forma especular, à luz de um passado exemplar, valendo-se de um teatro histórico. No prefácio, o autor já confessa que a peça estava em perfeita sintonia com os últimos acontecimentos em Coimbra, numa clara alusão aos dois regimes políticos da época: Absolutismo e Liberalismo. No prefácio da segunda edição, em 1830, admite que a intenção da peça é a moralidade política.

O assunto é o mais nobre, mais histórico e mais trágico de toda a história antiga e moderna. Representando as últimas agonias da mais solidamente constituída República da Antigüidade, - a moralidade política do drama naturalmente reflete muita luz sobre a grande questão que ora revolve o mundo e mostra (talvez mais claro que nenhuns tratados) a superioridade das modernas formas representativas, e a excelência da liberdade constitucional ou monárquica. (GARRETT, 1966, v. I, p. 1615)

Para tal propósito, o autor recorre aos anos da História Romana (47 a.C), para de lá trazer um dilema que, não obstante distanciado pelo tempo, iguala romanos e portugueses: o confronto República versus Ditadura, em Roma, serve de pretexto para o exame do Absolutismo e do Liberalismo, propostas políticas que agitavam Portugal desde 1820. É nesse contexto que Garrett mostra um passado romano que serve de modelo para o presente português.

Seu teatro, por este prisma, estaria comprometido com o esclarecimento da mentalidade pública. Se há um teatro que se presta a resgatar o nacionalismo adormecido, outro não é que o teatro histórico. "Os teatros, desde que pela civilização e bom gosto foram limpos das fezes da barbaridade, começaram a ser, não só a escola da boa e lídima linguagem, e da moral sã e pura, mas o incentivo da glória e o gérmen das virtudes sociais.” (apud MONTEIRO, 1971, v. I, p. 327)

As idéias estéticas de Garrett, defendidas por ele desde 1819, amadurecem a partir de 22 de novembro de 1836, ao ser nomeado Inspetor Geral dos Teatros, cargo oferecido por Passos Manuel, herói do Setembrismo e Primeiro-Ministro, em 1836. Entre o período de 1837 a 1844, Garrett desempenha várias atividades, sobretudo no 
campo intelectual e político, como embaixador, deputado e fundador do novo teatro português, além de escrever suas mais importantes criações dramatúrgicas: Um Auto de Gil Vicente e Frei Luís de Sousa.

Outro fato contribui para essa renacionalização: o desterro e as duas emigrações em Inglaterra e França (respectivamente, em 1823, 1824 e 1828), bem como a missão diplomática em Bruxelas (1834).

A título de exemplificação, em Catão, Garrett disfarçou o conflito português Liberalismo versus Absolutismo à romana no embate República e Ditadura. Em 1838, com a publicação de Um Auto de Gil Vicente, inspira-se na história, nas lendas e no folclore nacionais.

Cabe ressaltar a importância de duas obras em que Garrett reforça sua crença acerca do teatro como meio vital para a edificação de um povo e a literatura vista como diversão, instrução e edificação do leitor. São elas: Adozinda (1828) e Lírica de João Mínimo (1829). A primeira foi publicada em Londres e no prefácio está presente a preferência por temas nacionais e um resgate dos autores que já trilharam esse mesmo caminho: "Generalizar as belezas de nossos autores, familiarizar a nação com elas, desenganar a mocidade iludida, que sob a fé e palavra de pedantes e estrangeirados, cuida ser a nossa a derradeira literatura da Europa, quando em muitos pontos é ela a primeira.”(GARRETT, 1966, v. I, p. 604)

Em Lírica de João Mínimo, o autor assevera que “os teatros são os meios de publicidade para os verdadeiros e legítimos filhos do lusitano Apolo que desprezam a ridícula glória de autores impressos.” (GARRETT, 1966, v. I, p.1483-4) É clara a idéia de literatura para o autor: deve ser "útil à coletividade".

Assim, no período de 1828 a 1829, fica patente a função edificante da literatura (na qual a dramática tem grande importância), que vai apresentando cores lusitanas. $\mathrm{O}$ docere cum delectare das letras clássicas, que o inspirara em 1819 e 1820, assume um sotaque acentuadamente nacional.

A escolha para o cargo de Inspetor Geral dos Teatros, em 1836, não poderia ser mais justa. A visão de Garrett a respeito da Arte Dramática casava-se perfeitamente com a de Passos Manuel. Segundo o Primeiro Ministro, o teatro era uma "escola de bom gosto" e contribuía "para a civilização e aperfeiçoamento moral da Nação Portuguesa".

Em Portugal nunca chegou a haver teatro; o que se chama teatro nacional, nunca; até nisso se parece a nossa literatura com a latina, que também o não teve. A cena romana viveu sempre de empréstimos 
gregos, nunca houve renda própria; a nossa andou fazendo operações mistas com a Itália e Castela, até que, fatigada de uma existência difícil, toda de privações e sem glória, arreou a bandeira nacional, que nunca içara com verdadeiro e bom direito, e entregou-se à invasão francesa. (GARRETT, 1966, v.II. p. 1319)

Como se pode depreender, a idéia de Garrett reside no fato de que, sem um teatro nacional, a identidade do povo e seu verdadeiro nacionalismo jamais se desenvolveriam. Salienta, ainda, o fato de Portugal ter o modelo a ser seguido: Gil Vicente, como afirma na introdução de Um Auto de Gil Vicente: “... tinha lançado os fundamentos de uma escola nacional..."

Atente-se para o fato de que, entre 1819 e 1820, os modelos a serem seguidos eram os greco-romanos e que, sem um espaço físico o teatro não vingaria. Se o modelo a ser seguido mudou e se a necessidade de um espaço físico é premente para a edificação de um teatro nacional, o ponto crucial do projeto de 1819 continua exatamente o mesmo: “O teatro é um grande meio de civilização, mas não prospera onde a não há.” (GARRETT, 1966, v. II , p. 1320)

A fórmula do desenvolvimento deste grande meio de civilização residiria, então, em grandes autores, na criação de um espaço físico e, aliado a estes, no púbico, sem o qual o teatro não se sustenta. Entretanto, é necessário criar o gosto do público: "Depois de criado o gosto público, o gosto público sustenta o teatro.” (GARRETT, 1966, v. II, p.1320)

Moldar, ou melhor, tentar moldar o gosto do público através de traduções apressadas das óperas italianas, sobretudo de Metastásio, fora tônica no século XVIII, mas tal empresa significou obter resultado contrário. E o público acabou afastando-se do teatro.

Para Garrett, após Gil Vicente, o teatro ficara sem herdeiros. Com extrema lucidez, aponta a causa da decadência do teatro num país em que outrora havia dado provas, sobretudo com os autos vicentinos, de um teatro frutífero e inovador. Segundo o autor, para que o teatro prospere é necessário impulsionar simultaneamente um teatro material, bons dramas e uma plêiade de autores. Sem estes três elementos não há teatro. E assim, com o cargo de Inspetor do Teatro Nacional, e, concomitantemente, com a fundação do Conservatório Geral de Arte Dramática, Garrett sentiu a esperança de ver renascer aquele grande meio de civilização: o Teatro. Em 1838, ao elaborar o drama Um Auto de Gil Vicente, dizia que "tinha no coração e na cabeça - a restauração do 
nosso teatro- seu fundador Gil Vicente- seu primeiro protetor el-rei D.Manuel- aquela grande época, aquela grande glória- de tudo isto se fez o drama." (GARRETT, 1966, v.II, p. 1325)

Os três elementos essenciais para a implantação do teatro se presentificam nas palavras de Garrett: o teatro material (que seria o futuro D.Maria II), o drama, a peça elaborada por ele e cuja finalidade era servir de modelo aos futuros criadores de bons dramas. Eram, aliás, esses os objetivos defendidos por Passos Manuel e largamente aprovados por Garrett. Acrescente-se a esta fermentação artística os atores que seriam formados pelo Conservatório Geral de Arte Dramática.

Outro elemento aglutinador é o passado exemplar resgatado com as figuras do drama garrettiano: “aquela grande época, aquela grande vitória” que foi o reinado de D. Manuel, aliado ao fundador do teatro nacional, Gil Vicente. Não estaria Garrett querendo ser modelo para novos autores dramáticos - havia prêmios para as melhores peças escritas a partir de então -, ensinando-lhes uma fórmula a ser seguida? E não seria essa fórmula o resgate da cultura nacional via um teatro histórico?

Ao avaliar seu trabalho no tocante à restauração do teatro, Garrett demonstra uma grande satisfação, afirmando que "o público entrou no espírito da obra e aplaudiu com entusiasmo, não o autor, mas, certa e visivelmente, a idéia nacional do autor." (GARRETT, 1966, v.II, p. 1326) Entenda-se por “idéia nacional do autor” uma obra de fácil entendimento para o público e capaz de resgatar um passado modelar que servisse de paradigma ao momento presente.

Todavia, os planos garrettianos não se concretizaram. Em 10 de julho de 1841, a facção cabralista toma o poder e ele é demitido do cargo de diretor do Conservatório. Depois de proclamada a restauração da Carta, na cidade do Porto, Garrett e seus correligionários sofrem os "enxovalhos" do partido dominante. Estes acontecimentos permitirão a Garrett traçar com vigor as crises pelas quais passava o teatro português desde os finais do século XVI: "A primeira trouxe-lha o fanatismo de el-rei D.Sebastião e a perda da independência nacional. A segunda queimaram-lhe o pobre Antônio José. A terceira veio com a Ópera italiana e a perseguição do Garção. A quarta foi a invasão das macaquices francesas. Esta quinta é a do Salvatério. ${ }^{4}$ (GARRETT, 1966, v. II, p. 1161)

\footnotetext{
${ }^{4}$ O Salvatério seria o futuro Teatro Nacional D.Maria II. A não-construção de um Teatro Nacional constituiria a quinta crise da dramaturgia portuguesa.
} 
Em 1842, vem a lume a obra $O$ Alfageme de Santarém, quando Costa Cabral sobe ao poder e restaura a Carta, tornando-se o condutor da política nacional. A intenção da peça está delimitada no prefácio da primeira edição:

Quis-se pintar nesse quadro a face da sociedade em um dos grandes cataclismos por que ela tem passado em Portugal. O pintor isolou-se de todo sentimento e simpatia- paixões políticas, não as tem - para ver e representar, como eles foram, são e há-de ser, os dois grandes elementos sociais, o popular e o aristocrático. (GARRETT, 1966, v. II, p.1161)

Diante do caos político perpetrado por Costa Cabral, a resposta de Garrett, um monarquista constitucional, é uma crítica violenta e mordaz à direita cartista. Para levar seu intento, o "pintor" volta ao passado, e da Crônica de D. João I, de Fernão Lopes, resgata um episódio histórico que será trabalhado como alegoria do momento vivido por ele e seus contemporâneos em 1842.

Em 1843, publica $O$ Romanceiro e, mais uma vez, defende uma literatura de cunho nacional, afirmando que seu ofício é "popularizar estudo da nossa literatura primitiva, dos seus documentos mais antigos e mais originais, para dirigir a revolução literária que se declarou no país..." (GARRETT, 1961, p. 59) A fonte da literatura nacional seria, segundo Garrett, em $O$ Romanceiro, o estudo das primitivas raízes poéticas, os romances em verso e as legendas em prosa, as fábulas e crenças antigas, as costumeiras e as superstições de outrora.

Constata-se que, passados vinte e quatro anos (de 1819 a 1843), a releitura do passado como modelo para a sua contemporaneidade oitocentista persiste na concepção estética garrettiana. Contudo, nesse momento o passado modelar já não é mais o grecolatino, mas a crônica histórica portuguesa e seu folclore. Note-se, outrossim, que a aderência de Garrett ao Romantismo não é completa. A Arte Poética, de Horácio, mantém-se como uma Bíblia artística para ele, ressaltando-se o romantismo classicizado, colhendo nessa obra o princípio romântico de uma literatura nacional.

Em 1844, surge a obra-prima de Garrett, apontada por alguns críticos como a melhor obra dramática do Romantismo Português: Frei Luís de Sousa. A obra, antecedida por um valioso prefácio, representa a súmula do pensamento dramático do autor, podendo ser denominado de prefácio-testamento. O próprio autor acreditava ter chegado ao ponto fulcral de sua produção dramática. 
No prefácio, o autor recorda todos os pontos do projeto iniciado com Afonso de Albuquerque, colocado em prática, ainda que de forma tímida, com Catão, realizado de forma consistente e prática com O Auto de Gil Vicente e atingindo seu ápice com o Frei Luís de Sousa.

Ao retomar a idéia do poeta/cidadão, reafirma o papel do artista, a quem cabe "revestir os homens das formas mais populares e derramar assim pelas nações um ensino fácil, uma instrução intelectual e moral que, sem aparato de sermão ou prelecção, surpreenda os ânimos e os corações da multidão dos seus próprios passatempos." (GARRETT, 1966, v II, p.38)

Ensinar a multidão "sem aparato ou prelecção" só seria possível com o gênero que o autor dominava e amava desde a mais tenra idade. "Assim quase que dou aqui o último vale a essa amena literatura que foi o mais querido folguedo da minha infância, o mais suave enleio da juventude e o passatempo mais agradável dos anos de hombridade." (GARRETT, 1966, v. II, p. 38)

É evidente, a partir do exposto, a paixão de Garrett pelo teatro que, de forma incansável, procurou ler sua contemporaneidade, examiná-la, criticá-la à luz alegórica de situações pretéritas.

O percurso feito até aqui permite uma reflexão: o drama e a ficção históricos, para Almeida Garrett, não ser resumem apenas em idealizar o passado glorioso de Portugal, trazendo-o como exemplo para o presente. Na verdade, além de oferecer o passado exemplar, o autor quis ler alegoricamente o presente via situações pretéritas, que é o viés mais importante e representativo da obra dramática desse autor, tornando-a engajada.

Como já explicitara em Frei Luís de Sousa, buscou no romance, na novela e no drama histórico a verdade do passado, oferecendo-o como um espelho em que se mire, a si e ao seu tempo, a sociedade sua coetânea. 


\section{Referências Bibliográficas}

BARATA, José Oliveira. História do Teatro Português. Lisboa: Universidade Aberta, 1991.

BRAGA, Teófilo. Garrett e os Dramas Românticos. Porto: Chandron, 1905.

GARRETT, Almeida. Obras de Almeida Garrett. Porto: Lello e Irmão-Editores, 1966, vol I e II.

. Doutrinas de Estética Literária. Lisboa: Seara Nova, 1961.

MARTINS, Oliveira. História de Portugal. Lisboa: Guimarães Editores, 1968.

MONTEIRO, Ofélia Paiva. A formação de Almeida Garrett. Experiência e criação. Coimbra: Centro de Estudos Românticos, 1971, 2 vols.

SARAIVA, José Hermano. História de Portugal. Lisboa: Publicações Europa-América, 1993. 